\title{
RESULTS OF THE PUTTI-PLATT OPERATION FOR RECURRENT ANTERIOR DISLOCATION OF THE SHOULDER
}

\author{
M S Islam ${ }^{1}$, R R Kairy ${ }^{2}$, M Islam ${ }^{3}$, R M Manzur ${ }^{4}$ and N F Islam ${ }^{5}$
}

\begin{abstract}
This was a prospective clinical trial carried out at NITOR, Dhaka from July 2004 to June 2006 involving 18 patients with recurrent anterior dislocation of the shoulder. All the cases were managed by Putti-Platt operative procedure. The aim of this study was to evaluate the effectiveness of the PuttiPlatt procedure in the management of recurrent anterior dislocation of the shoulder. In this study, purposing sampling methods were followed irrespective of sex. Most common age group in this series was 21-30 years. This prospective clinical study comprised with 18 patients, 16 cases $(88.88 \%)$ showed excellent and good results and 2 cases (11.11\%) showed fair results. Therefore, Putti-Platt procedure can be considered as an effective procedure in the treatment of recurrent anterior dislocation of shoulder. Less tissue handling, close postoperative follow-up and active muscle exercise is essential for producing good result. The long-term result is beyond the scope of this study. Long-term follow up is needed to evaluate the final out come of these patients.
\end{abstract}

\section{INTRODUCTION}

The bony anatomy of the shoulder joint does not provide inherent stability. The shoulder, by virtue of its anatomy and biomechanics, is one of the most unstable and frequently dislocated joints in the body, accounting for nearly $50 \%$ of all dislocations (Phillips, 2003). There is no essential pathological lesion responsible for every recurrent subluxation or dislocation of the shoulder. Cause of the recurrent dislocation is still a matter of debate. It has been implicated on many factors but the chief factor was thought to be failure to immobilize the shoulder for proper period of time after reduction of an initial dislocation. But the current concept has identified number of other more important factors like the site and nature of the damage at the time of the initial dislocation (McLaughlin and Cavallaro, 1950) \& (McLaughlin and MacLellan, 1967), severity of the trauma causing the initial dislocation (Rowe, 1963), the age of the patient at the time of the initial dislocation (Hovelius, 1987) \& (Rowe and Sakellarides, 1961) \& (McLaughlin and Cavallaro, 1950).

There is no single essential lesion is responsible for every recurrent dislocation of the shoulder. Stability of this inherently unstable joint depends on a continuing balance between the static and dynamic mechanisms influencing motion and stability. In addition to the various possible primary deficiencies like laxity of the capsule influencing instability, secondary deficiencies like Hill-Sachs lesion can occur when repeated dislocations have occurred. Erosion of the anterior glenoid rim, stretching of the anterior capsule and subscapularis tendon, and fraying and degeneration of the glenoid labrum can all occur with repeated dislocation. The primary deficiency, as well as the

\footnotetext{
Assistant Professor, Chittagong Medical College Hospital, Chittagong, Bangladesh,

Professor, National Institute of Traumatology and Orthopedic Rehabilitation (NITOR), Dhaka, Bangladesh.

IMO, Chittagong Medical College Hospital, Chittagong, Bangladesh•

Resident, National Institute of Traumatology and Orthopedic Rehabilitation (NITOR), Dhaka, Bangladesh -

Assistant Registrar (Casuality), Dhaka Medical College Hospital, Dhaka, Bangladesh.
} 
secondary deficiencies, will need to be considered at the time of surgery and in postoperative rehabilitation to correct the instability. Since no single deficiency is responsible for every recurrent dislocation of the shoulder, no single operative procedure can be applied to every patient. The surgeon must carefully search for identify the deficiencies present in order to choose the proper procedure.

More than 150 operations and many modifications of the some have been devised to treat traumatic recurrent anterior instability of the shoulder (Pritsch et al., 1983). There is no single best procedure. There are no generally accepted concepts for the treatment of traumatic anterior shoulder dislocation. Factors that have been stressed as important in achieving a successful result are adequate exposure and accurate surgical technique. The pathological condition should be defined and a procedure performed that corrects this condition most anatomically. Ideally, the procedure for recurrent instability should include the following factors: (i) low recurrence rate, (ii) low complication rate, (iii) low re-operation rate, (iv) does not harm (arthritis), (v) do not restrict motion, (vi) is applicable in most cases, (vii) allows observation of the joint, (viii) corrects the pathological condition, and (ix) is not too difficult to perform (Phillips, 2OO3).

\section{Rationale:}

In this study, resilience of The Putti-Platt procedure for the management of the anterior recurrent dislocation of shoulder was assessed

\section{Hypothesis:}

Futti-Platt procedure is an effective procedure for the management of the recurrent anterior dislocation of the shoulder.

\section{Aims of the study:}

Effectiveness of The Putti-Platt procedure in the management of recurrent anterior dislocation of the shoulder.

\section{Objectives of the study:}

1. To find out the age, sex incidence and predominant side of injury.

2. To see the effect of the procedure on range of motion, pain tunition and stabilizing of shoulder.

\section{PATIENTS AND METHODS}

Type of study: A clinical trial.

Place of study: National Institute of Traumatology and Orthopedic Rehabilitation (NITOR), Dhaka.

Period of study: This study was conducted during the period from July 2004 to June 2006.

Selection of cases: The patients irrespective of sex, with history of the anterior recurrent dislocation of shoulder, traumatic origin.

Sampling method: Purposive sampling method was followed as per inclusion and exclusion criteria. The diagnosis of the recurrent anterior dislocation of the shoulder was done from history and the findings of clinical examination.

Sample size: 18

\section{Inclusion criteria:}

1) Recurrent dislocation

2) Traumatic without fracture

3) Supple shoulder joint

\section{Exclusion criteria:}

1. Fracture dislocation. 
2. Without epiphyseal fusion.

3. Pathological recurrent dislocation and fractures.

4. Restricted movement of the shoulder.

\section{Procedure:}

Data collection: A per-designed pro-forma containing history and examination findings of the patient, operative procedure and follow-up criteria was used to collect the data.

Data Analysis: The collected data was compiled and tabulated according to key variables. The analysis and interpretation of the data was performed using different statistical methods and formula.

Evaluation of the final outcome: Evaluation of the final outcome was based on the C.R ROWE grading system.

Measures of variables: After enrolment of the patient and tabulation of the collected data following outcome variable were measured:

a) Demographic variable

1) Age

ii) Sex

b) Clinical variable

- Nature of initial injury

- Treatment of initial dislocation

- Side of involvement

c) Outcome variable

- Function

- Pain

- Stability

- Motion

Ethical issues: Informed written consents from all patients included in the study was taken before hand.

Surgical Procedure: Putti-Platt procedure.

Rehabilitation: The postoperative rehabilitation program actually began pre-operatively, when the patient was instructed in a physician-directed stretching and strengthening program. We asked patients to perform these exercises a minimum of five times daily and emphasize that they were responsible to a large degree for the final outcome of the surgery by their participation in the exercise program. The body bandage was discontinued after 3 weeks and the patient was instructed to increase the use of the operated extremity for daily living activities. These activities can include dressing, combing hair, brushing teeth, eating and also shoulder stretching exercise. After 8 weeks, muscle building and strengthening exercises began.

We allowed patients to return to activities commensurate with their strength. Patients were not being allowed to return to heavy manual labor or sports until they have regained a range of motion near to that of the opposite side and have approximately $85 \%$ to $90 \%$ of the strength in their opposite extremity which generally took about 5 to 8 months. We cautioned patients, especially those in their second and third decade of live, that maintenance of shoulder stability and strength necessitates a commitment to continuing their exercise program two or three times per week once their formal rehabilitation is completed. (Dana, Michael \& Charles 1997) \& (Burkhead \& Rockwood 1992) 


\section{Observation and results}

This prospective clinical study was carried out at NITOR, Dhaka from July 2004 to June 2006 involving 18 patients with recurrent anterior dislocation of shoulder. Every body was treated by PuttiPlatt procedure. In this series C.R. Rowe grading system was used to evaluate results. Excellent and good results were taken as satisfactory result. Fair and poor results were taken as unsatisfactory result.

Age and sex incidence: This clinical trial comprises 18 young patients with recurrent anterior dislocation of shoulder. Their ages varies from 16 to 35 years with an average 25.4 years. In this clinical trial, 17 patients were male and 1 was female.

Table 1: Distribution of patients by age groups.

\begin{tabular}{|l|l|l|l|}
\hline Years & No. of patients & Percentage & Average \\
\hline $10-20$ years & 3 & $16.6 \%$ & \\
\cline { 1 - 3 } $21-30$ years & 12 & $66.6 \%$ & \multirow{2}{*}{25.4 years } \\
\hline $31-40$ years & 3 & $16.6 \%$ & \\
\hline Total & 18 & $100 \%$ & \\
\hline
\end{tabular}

Occupation: Out of 18 patients, 7 patients were student, 3 were farmer, 3 were electrician, 2 were businessman, 2 were BDR and 1 was housewife.

Table 2: Occupation status of the patients.

\begin{tabular}{|l|c|c|}
\hline Occupation & No. of case & Percentage \\
\hline Student & 7 & $38 \%$ \\
\hline Farmer & 3 & $17 \%$ \\
\hline Businessman & 2 & $11 \%$ \\
\hline BDR & 2 & $11 \%$ \\
\hline Electrician & 3 & $17 \%$ \\
\hline Housewife & 1 & $6 \%$ \\
\hline
\end{tabular}

Shoulder involved: Out of 18 cases, left side was affected in 10 cases and right side in 8 cases.

Table 3: Side involvement of patients.

\begin{tabular}{|l|c|c|}
\hline Side & No. of case & Percentage \\
\hline Left & 10 & $56 \%$ \\
\hline Right & 08 & $44 \%$ \\
\hline Total & 18 & $100 \%$ \\
\hline
\end{tabular}

Table 4: Dominant/Non-dominant.

\begin{tabular}{|l|c|c|}
\hline & No. of case & Percentage \\
\hline Non-dominant & 10 & $56 \%$ \\
\hline Dominant & 08 & $44 \%$ \\
\hline Total & 18 & $100 \%$ \\
\hline
\end{tabular}


Table 5: Frequency of dislocation before surgery.

\begin{tabular}{|l|c|c|}
\hline Frequency of dislocation & No. of case & Percentage \\
\hline Less than 5 & 5 & $28 \%$ \\
\hline $5-10$ & 10 & $55 \%$ \\
\hline $11-16$ & 0 & $0 \%$ \\
\hline More than 16 & 3 & $17 \%$ \\
\hline Total & 18 & $100 \%$ \\
\hline
\end{tabular}

Initial trauma: The most common initial trauma was sports injuries 10 cases, road traffic accident 4 cases and others 4 cases.

Table 6: Initial trauma.

\begin{tabular}{|l|c|c|}
\hline Cause of initial trauma & No. of case & Percentage \\
\hline Sports & 10 & $56 \%$ \\
\hline RTA & 4 & $22 \%$ \\
\hline Others & 4 & $22 \%$ \\
\hline Total & 18 & $100 \%$ \\
\hline
\end{tabular}

Length of immobilization after first dislocation: A total of 8 cases were immobilized up to 1-10 days, 5 cases were immobilized up to 11-21 days and no immobilization done in 6 cases.

Table 7: Length of immobilization after first dislocation

\begin{tabular}{|l|c|c|}
\hline Length of initial immobilization & No. of case & Percentage \\
\hline $1-10$ days & 8 & $44 \%$ \\
\hline $11-21$ days & 5 & $28 \%$ \\
\hline No immobilization & 5 & $28 \%$ \\
\hline Total & 18 & $100 \%$ \\
\hline
\end{tabular}

Final Rowe Score:

Table 8: Final Rowe Score.

\begin{tabular}{|l|c|}
\hline Case No. & Rowe Score \\
\hline 1 & 95 \\
\hline 2 & 95 \\
\hline 3 & 75 \\
\hline 4 & 90 \\
\hline 5 & 90 \\
\hline 6 & 95 \\
\hline 7 & 95 \\
\hline 8 & 90 \\
\hline 9 & 80 \\
\hline 10 & 95 \\
\hline 11 & 75 \\
\hline 12 & 70 \\
\hline 13 & 55 \\
\hline 14 & 80 \\
\hline 15 & 75 \\
\hline
\end{tabular}




\begin{tabular}{|l|c|}
\hline Case No. & Rowe Score \\
\hline 16 & 80 \\
\hline 17 & 60 \\
\hline 18 & 75 \\
\hline
\end{tabular}

Case no. 13 did not follow advice properly and timely.

\section{Clinical results:}

Table 9: Clinical results of the present series.

\begin{tabular}{|l|c|c|}
\hline Results & No. of patients & Percentage \\
\hline Excellent & 8 & $45 \%$ \\
\hline Good & 8 & $44 \%$ \\
\hline Fair & 2 & $11 \%$ \\
\hline Poor & 0 & $0 \%$ \\
\hline Total & 18 & $100 \%$ \\
\hline
\end{tabular}

Overall results: In this series, 16 cases were satisfactory and 2 cases were unsatisfactory.

Table 10: Overall results of the present series.

\begin{tabular}{|l|l|l|l|}
\hline Results & No. of case & Percentage & Remark \\
\hline Satisfactory & 16 & $89 \%$ & $\chi^{2}=\mathrm{P}<$ \\
\cline { 1 - 2 } Unsatisfactory & 2 & $11 \%$ & \\
\cline { 1 - 3 } Total & 18 & $11 \%$ & \\
\hline
\end{tabular}

\section{DISCUSSION}

Present series, which included 18 patient of recurrent anterior dislocation of shoulder, treated by PuttiPlatt procedure with a average length of follow-up was 12.6 months.

In this series, recurrent dislocation of shoulder was more in man than woman. It was observed only in one woman out of 18 cases. Similar sex incidence was observed by Hovelius et al. (1979) and also by Brav (1955) (36 males and one female).

In this series, recurrent anterior dislocation of shoulder most commonly occurred in age group of 2I-30 years with an average of 25.4 years. This result is in agreement with the statistical study of Brav (1955) who observed common age group of 18-41 years with an average of 23.4 years. In a review article, Robinson and Dobson (2004) reported that a sum of $50 \%$ of recurrent dislocation of shoulder had occurred in between 20-30 years.

Length of immobilization after reduction of initial dislocation was very much important. In the present series, only 8 cases were immobilized up to 1-10 days, 5 cases were immobilized 11-21 days and no immobilization was done in 5 cases. In a study of Brav (1955), only seven patients stated that there was immobilization of the shoulder following the original dislocation. Thirty-four initial dislocations $(82.9 \%)$ were either treated by a simple sling or were not treated at all. Concerning the duration of original treatment only eight dislocations were treated for a period longer than two weeks. In thirtythree dislocations $(80.5 \%)$, there was either no immobilization or immobilization was discontinued at the end of two weeks.

Many of the initial dislocation usually originated in body contact athletics/ sports. In this series, it was observed that 10 cases $(55.5 \%)$ out of 18 cases occurred due to various sporting activities. Lipscomb (1975) described same observation. Brav (1955) also described same observation (23 cases due to sporting activities out of 30 cases).

Putti-Platt procedure can be done through classic deltopectroal approach and anterior axillary approach. In this series, Putti-Platt procedure was done through anterior arillary approach which had 
some advantages like good exposure, minimal blood loss and a cosmetically desirable scar. Zenni (1978) observed similar things in his study.

In this series, it was observed that the limitation of external rotation with an average was $18.4^{0}$. MacDonald et al. (1992) stated that a limitation of at least 25 degrees of external rotation after an anterior procedure for recurrent dislocation of the shoulder was not only inevitable but also desirable and acceptable. In this series, limitation of external rotation less then usual average external rotation due to double breasting of subscapularis done in neutral position of shoulder in classic Putti-Platt these done in $10^{\circ}$ internal rotation of shoulder joint.

In the clinical results of this series, 8 cases $(44.44 \%)$ were excellent, 8 cases $(44.44 \%)$ were good and 2 cases $(11.11 \%)$ were fair. These results are in similarity with the study conducted by König et al. (1997) who observed 13 cases (50\%) as excellent, 3 cases as good, 7 cases as fair and 3 cases as poor.

\section{REFERENCES}

Brav Colonel Ernest A. 1955. 'An evaluation of the Putti-Platt reconstruction procedure for recurrent dislocation of the shoulder'. J. Bone \& Joint Surgery. Vol. 37(A), No. 4, pp. 731-41.

Hovelius, L.; Thorling, J. and Fredin, H. 1979. 'Recurrent anterior dislocation of the shoulder: Results after the Bankert and Putti-Platt operations'. Journal of Bone Joint Surgery Am. Vol. 61, No. 4. pp. 566-9.

Hovelius, L. 1987. 'Anterior dislocation of the shoulder in teen-agers and young adults'. Journal of Bone Joint Surgery. Vol. 69(A). p. 393.

König, D.P.; Rütt, J.; Treml, O. and Hackenbroch, M.H. 1997. 'Osteoarthritis and recurrences after Putti-Platt and Eden-Hybbinette operations for recurrent dislocation of the shoulder'. International Orthopaedics. Vol. 21, No. 2. pp. 72-76.

Lipscomb, A.B. 1975. 'Treatment of recurrent anterior dislocation and subluxation of the glenohumeral joint in athletes'. Clin. Orthop. Vol. 109. pp. 122-5.

MacDonald, P.B.; Hawkins, R.J.; Fowler, P.J. and Miniaci, A. 1992. 'Release of the subscapularis for internal rotation contracture and pain after anterior repair for recurrent anterior dislocation of the shoulder'. The Journal of Bone and Joint Surgery. Vol. 74(5). pp. 734-737.

McLaughlin, H.L. and Cavallaro, W.U. 1950. 'Primary anterior dislocation of the shoulder'. American Journal of Surgery. Vol. 80. p. 615.

McLaughlin, H.L. and MacLellan, D.I. 1967. 'Recurrent anterior dislocation of the shoulder II: A comparative study'. Journal of Trauma. Vol. 7. p. 191.

Phillips, B. Barry. 2003. 'Recurrent dislocation'. Campbell's Operative Orthopaedics. Vol. 3, 10 ${ }^{\text {th }}$ edn, Canale, Mosby Press, Pennsylvania, pp. 2397-2404.

Pritsch, M.; Engel, J.; Horoszowski, H. and Farin, I. 1983. 'Recurrent dislocation of the shoulder and the Putti-Platt operation'. Arch. Orthop. Trauma Surgery. Vol. 101, No. 2. pp. 133-5.

Robinson, C.M. and Dobson, R.J. 2004. 'Anterior instability of the shoulder after trauma'. J. Bone Joint Surg. (Br). Vol. 86(4). pp. 469-479.

Rowe, C.R. and Sakellarides, H.T. 1961. 'Factors related to recurrences of anterior dislocations of the shoulder'. Clinical Orthop. Vol. 20. p. 40.

Rowe, C.R. 1963. 'The results of the operative treatment of recurrent dislocations of the shoulder'. Surg. Clin. North Am. Vol. 43. p. 1667.

Zenni, E.J. Jr. 1978. 'An axillary approach for a Putti-Platt repair’. Clin. Orthop. Vol. 136. pp. 157-9. 